\title{
Stock Exchange Frequent Topics @NYSE
}

\author{
Dewi Anggraini Faisol ${ }^{1} \quad$ Janfry Sihite ${ }^{2 *}$ \\ 1.Department of Accounting, Universitas Mercu Buana, Indonesia \\ 2.Department of Management, Universitas Mercu Buana, Indonesia
}

\begin{abstract}
The utilization of Twitter content to predict the market is necessary since the fundamental perception related to the activities of the market influenced by the opinion in the market space. Therefore this research is utilizing the tweet of @NYSE and compare the research finding @IDX_BEI the stock exchange office in Indonesia. There is 2069 tweet extracted from the period January until June 2018. Further analysis using the Exploratory Factor Analysis conducted, and show that @NYSE delivering more varieties of information related to the stock market. It is not only information related to the IPO, but also an opinion from the recognized economist and analyst. The findings show that Twitter could be improved for further utilization and reduce asymmetric information related to the market
\end{abstract}

Keywords: @NYSE, Frequent Topics, Unstructured Dataset

DOI: $10.7176 /$ RJFA/10-16-10

Publication date: August $31^{\text {st }} 2019$

\section{Research Background}

The numbers of people that using a smartphone is growing significantly, more than 400 million of Indonesian that has a smartphone, and also hundreds of millions of people in America that using a smartphone. The smartphone supports the analyst, investor to reach the information and opinion within the market space; they could also capture information related to the future projection of the stock market.

One of the contents that influence the volume of stock trading and also the volatility of the market is the Twitter content. The corporation delivering information to reduce the asymmetric information in the market via Twitter. Therefore, there is necessary research that should be conducted to explore findings related to the market.

Nevertheless, there is still a lack of research that utilizes the unstructured data set twitter since the body of knowledge for analyzing the Twitter content is still in the early phase. Therefore, research conducted for the stock market office like@IDX_BEI and @NYSE is necessary to expose the insight.

The previous research findings show that @IDX_BEI mostly deliver information related to the corporation IPO. Nevertheless, the application of twitter could reach many investors and influence a variety of stakeholders. The potential utilization and the potential benefit is higher compare with only delivering information.

This research conducted to compare @NYSE and @IDX_BEI. Therefore, we could improve the utilization and also delivering a recommendation to improve the utilization of Twitter and reduce the asymmetric information in the market. This research is the second phase of analyzing tweet delivered on Twitter from the @NYSE office stock market office, and the first phase is the @IDX BEI research. Therefore, further research utilizing the feeds and also the content in the market space is necessary to be able to deliver a recommendation to the stock market office.

\section{Theoretical Review}

The tweet is a media to delivering an opinion related to the investment in the financial markets. StockTwits is one of the Twitter that delivers an investment opinion that could be accessed by the public (Tu, Yang, Cheung, \& Mamoulis, 2018). The vast number of tweet content related to investment opinion could help the asymmetric information of the market; nevertheless, when there is too many information, it could be confused with the market. Therefore the research using multiple categories of factors that generate from the profile of the author of the information. Categorizing the content of the opinion and also the characteristic of stock that are discussed in the tweet delivered. This quality of background information is essential. Therefore the consumer could categorize the high-quality opinions that produce by the credible author. Credibility is essential since there are many tweets delivered; therefore, to help the netizen simplifying the decision making the process in the stock market.

We should develop a method to understand the market and getting insight from the tweet faster. The faster the information delivered is essential since it is related to the responsiveness in the stock market decision-making process. Twitter responsiveness to deliver information that recognizes as the push technology. Could help the public to use information in the market, supporting to reduce the asymmetric information, since the producer of the information such as the official corporation could deliver any formation immediately after some decision or some action party taken by the corporation (Mazboudi \& Khalil, 2017).

This research shows that many corporations choose to announce their acquisition on Twitter, and it helped the market to anticipate an adverse reaction from the activity of acquisition. Therefore this research shows that 
twitters beneficial to reach the consumer worldwide. The asymmetric information is crucial since it could manage the stock price stability in the acquisition activity.

Twitter deliver tweets that affects the stock prices, and it also influences the market and the investor decision. Therefore we could see that the Twitter tweet and posting have the predictive power toward the market because it influences the perception of the reader which is the investor that acquired the information to be able to respond fast related to the movement in the market (Nasseri, Tucker, \& de Cesare, 2015).

StockTwits is one of the twitter researched, which is the tweet content related to the investor opinion toward the future market. The research experiment conducted to 122 Twitter trading strategies, and show that there is a promising performance related to the relationship of stock and the posting. Therefore posting could influence the stock activities in the capital market.

The market influenced by many things since there are many indicators related to the corporation stock, such as the economy microeconomics, the regulation of the market, the competitor activities, and also many related activities could influence the future projection of the stock (Corea, 2016).

Therefore to simplify the analysis related to these indicators, an investor could see how the market reacts toward each indicator in the discussion that we could access worldwide. We could be able to see the movement of the opinion delivered by the investor in Twitter real-time. Therefore the Twitter data could predict and have the explanatory power to predict the market.

The benefit of the Twitter post to the stock market could be explained by the research that analyzes the Dow Jones, NASDAQ and SP 500. The research collected the tweet from Twitter Stockfits for six months (Zhang, Fuehres, \& Gloor, 2011).

The significant volume of data set analyzed, and the researchers conclude that there is a correlation between the tweets and the indicators. The findings significantly show that there is a significant negative influence of emotional tweet toward the Dow John stock and S\&P 500. These findings show the importance of analyzing Twitter content. The information related to the content to predict how the stock market projection the next day when the market is opening.

The financial technic analysis comes from how the time series of data in the financial market, and this financial time series data background related to the activity of the stock that influenced by the qualitative information related to the fundamental assumption (Atkins, Niranjan, \& Gerding, 2018). This qualitative assumption, such as the news, the projection of the future market will influence the behavior of the investor. The behavior captured in the time series financial markets data.

Therefore to be able to make the right prediction, we should combine these two types of data set, which is the time series financial market and also the qualitative that come from the news. One of the information that we could gather and have the predictive power to project the market is Twitter content. The researchers conclude that the volatility the movement of the stock market is predictable compare with the asset price movement when we are using the news for a financial from the machine learning input.

Oliveira is examining the video of microblogging data to forecast the stock market variables, which are the returns, volatility, and also the volume of trading. The research collected the data and also used the sentiment and attention indicators extracted from the microblogs (Oliveira, Cortez, \& Areal, 2017).

The research found that sentiment and also posting is relevant to forecast the stock in the S\&P 500 index, the capitalization of the lower market. Finally, this is another research that confirms microblogging data, which are the Twitter dataset could predict the stock market and providing available insight related to the methodology that the consumer could use to predict the future stock market prices.

It stated that the social media platform could simplify the intermediation of media. Therefore every company could establish the Twitter account and delivering information to the target market. There is a stock market corporation that examines in this research, analyzing Twitter from the samples of NYSE stock exchange corporation ( $\mathrm{Liu}, \mathrm{Wu}, \mathrm{Li}, \& \mathrm{Li}, 2015$ ).

The research findings show that the Twitter activity could predict the comovement of stocks, the firms or corporation with the official Twitter accounts have more significant comovement compare with the corporation that did not have the official Twitter account. Therefore this research shows the importance of information from the Twitter account that could influence the stock movement.

There are many discussion and popular topic about the stock market on Twitter. A volatile quantity of Twitter delivered about the market related to the price and the stock option. Interesting findings show that after a spike in Twitter volume, there is a significantly lower volume of Twitter compare than before the spike (Wei, Mao, \& Wang, 2016).

This research finding shows that there is a variety of interest related to the stock market. A reason that explains the number of the volume of Twitter that lower significantly after the spike, because there is a moment when the market is waiting or putting the options open. Since the stock options that appear to be favorable still overpriced. Therefore the interest in the tweeting related to the stock price is lower.

Research conducted by Al Nasseri analyzing only in tweets from the StockTwits to look about the relationship 
of disagreement indicator in the StockTwits toward the stock returns and trading volume (Al-Nasseri \& Menla Ali, 2018). There are a variety of opinions that categorized into a negative or positive during the bull (bear)ish market periods. The findings show that the higher online disagreement will increase the trading volume, and the portfolio strategies designed based on the disagreement indicator could generate abnormal profits. The research findings show the benefit of analyzing online stock twits and exploring the indicator that could affect the general perception of the market that are reading the online tweets to gather information related to the decision making to select the prospective stock market.

\section{Research Method}

There are many benefits of the text mining, to explore the attributes of the company marketing communication, explore the preference of the consumer behavior, and also define the indicators that relate to the stock market prediction. Text mining could solve some problems in financing through a prediction related to the stock market (Kumar \& Ravi, 2016). Text mining has some technics to analyze the corpus of the text for data. The importance of text mining is to discover insight from the unstructured data set (Dörre, Gerstl, \& Seiffert, 1999). Therefore there are a minimum of two steps on the methodology, the text preprocessing and the knowledge extraction.

In the text group preprocessing, we are preparing the data to be able to analyze with the software analysis. Since most of the tweet is the unstructured data set, therefore, we should clean the data (Salton \& McGill, 1983). We could also look for a tweet that is not necessary to process for further analysis. Moreover, after the dataset is clean, we could also make an abbreviation or dictionary related to the tweet and correcting the typo.

The findings quality depend on data preprocessing (Uysal \& Gunal, 2014). Therefore, after the data is clean, we could move to the selected project, which is analyzing the dataset. The text mining application such as classification, clustering, and text summarization, and also topic detection or identification, and the last is the association of rule mining. This application will be beneficial to get insight related to the data processor. Furthermore, the analysis will conduct a dimension reduction (Yang \& Pedersen, 1997), evaluate the document frequency, and also the co-occurrence and association of terms in the text corpus (Feldman \& Hirsh, 1996).

The unit observes it is@NYSE, selected to be the sample of this research since@NYSE is one the leading stock exchange in the world. The sample represents the established and modern stock exchange. The data extracted from the twitter channel @NYSE. The dataset selected from January until June 2018. There is 2069 tweet that process for further analysis; the dataset represents the activities@NYSE to the targeted market.

\begin{tabular}{|c|c|c|c|}
\hline $\begin{array}{c}\text { Data Extraction } \\
@ N Y S E\end{array}$ & Data Preparation & $\begin{array}{c}\text { Exploratory Factor } \\
\text { Analysis }\end{array}$ & Findings \& Discussion \\
\hline 2069 Dataset & $\begin{array}{c}923 \text { Tweet \& } \\
1146 \text { ReTweet }\end{array}$ & 14 Themes & People \\
\hline
\end{tabular}

Figure 1. Research Process

The data processing start with data preparation, taking out the second posted tweet (Figure 1). Furthermore, after the data cleaning, further analysis conducted. The process is an exploratory factor analysis with the Provalis research software will expose the insight of dataset these into selected themes.

The relationship within the tweet dataset will show the insight within the data, and the tweet analyzed with the exploratory factor analysis technique (Wijanto, 2008) (Hair, Anderson, Tatham, \& William, 1998). Since there is a lack of theory related to the stock market and tweet dataset utilization, the exploratory factor analysis conducted. The exploratory factor analysis had been conducted for varieties of case study such as the kitchen application (Sihite, 2019b), hospitality (Nugroho, 2018b) (Nugroho, Sihite, \& Harwani, 2019), online transportation (Sihite, 2019a), coffee shop (Harwani \& Sihite, 2019), National Tourism Organization (Sihite \& Nugroho, 2018) (Nugroho \& Sihite, 2018) (Nugroho, 2017), education (Nugroho \& Janfry Sihite, 2015a) (Nugroho \& Janfry Sihite, 2015b), banking (Nugroho \& Sihite, 2016) (Nugroho, 2018a), and the airline (Sihite, Harun, \& Nugroho, 2015) (Nugroho \& Janfry Sihite, 2015).

After the complexity of the data reduced to a specific dimension (Campbell, Pitt, Parent, \& Berthon, 2011), therefore, we could interpret the themes of the exploratory factor analysis. Provalis Research Software consists of the QDA Miner to identify the relationship between keywords utilized for the exploratory factor analysis (Silver \& Lewins, 2014).

\section{Results and Discussion}

The exploratory of the unstructured tweet dataset from the Twitter@NYSE, delivering some findings (Figure 2). The first topic from 8 March 2018 discussing Stacey Cunningham which is the first woman president for the New York Stock Exchange. Stacey Cunningham is the woman in corporate leadership. Furthermore on 31 January 2018 tweet, there is also information related to NYSE COO (Chief Operating Officer). @NYSE retweeting the information from@Niri_nasional on 6 January 2018,@Niri nasional promoting the event that Stacey Cunningham will attend, the event will be held on 12 June 2018. Moreover, @Niri_nasional is an association of 
professional investor relations in the world.

The ICE (Intercontinental Exchange) is NYSE Fang Plus index that is posted by NYSE on 23 January 2018. FANG created for the technology stocks, which are Facebook, Amazon, Netflix, and Google. ICE also add Apple, Baido, Alibaba, Twitter, Tesla, and Nvidia in the index. This index has the same weight, that means that every stock in NYSE FANG Plus index has the same weight, regardless of the stock capitalization of each company. Ice market is a market data that is important to all asset-management class, and the data will be delivered globally through technology connection, based on the expertise that is safe and flexible.

There is also information about Mike Ritland, the founder@warriordogs that on 3 January 2018 introduced as the founder of the soldier dog foundation that serves for the military K9. They are just starting trading. It is also like@QIAGEN that on 10 January 2018 celebrating the first day of training in NYSE.

@NYSE also post the 23 January 2018 event when they are accepting client inside ETF to discuss the NYSE Arc that has the answer to all the ETF needs. ETF is the exchange-traded funds that are combining the trading characteristics with the diversity mutual fund risk, and make the product more transparent, flexible, and cost less.

The closing bell topic is discussing the bell for the closing of the second anniversary of @ cheddar — the post delivered on 2 January 2018. There is also a twit related to Regency Center Corporation rings the closing bell. Regency Center Corporation rings the bell to celebrate the anniversary of the listed company in NYSE. On 11 January 2018, there is also a topic related to the opening. @NYSE delivering information to the netizen related to the live event of opening bells for PVH Corp for the brand speedo.

The topic of chatting with Cheddar and Kristen Scholer is related. Kristen Scholer is one of the anchors for business, technology, and media in New York City. The company is delivering information on business and technology and cooperating with NYSE. There is also information about Mkobach, the account for Matthew Kobach, which is monitoring every content in social media for the New York Stock Exchange, managing the social content for ICE, Intercontinental Exchange Data services, and also social media marketing data services.

Jeff Sprecher is a businessman and also the chief and CEO for Intercontinental Exchange or the ICE markets and also the Chief for the New York Stock Exchange. The information delivered by @NYSE on 3 April 2018, Jeff Sprecher, the CEO of ICE joins the podcast. Ice market is the renewal of all ICE market and international exchange.

On 12 March 2018,@NYSE posting information about Bruce Bond, the co-founder, and CEO of innovator capital management that joined the podcast at and YSE. The twitter@NYSE is sharing information when they are visiting NRF18 or the North Star Realty Finance 2018 to learn about the future of retail from the @NYSE Snapchat.

The ETF or the exchange-traded funds is the mutual fund that treated like stocks. Therefore the ETF is an efficient investment. The topic in this attribute is discussing the NYC Arca, the United States exchange stock exchange that traded in the ETF. It is also trading 8000 security bond listed in the United States. A trader who used Arca can play and using the area to access an open market and directly executing an electronic transaction efficiently and fast in every American stock exchange.

The topic New York stock exchange is one of the biggest stock exchange in the world. @downtownNYC is the Twitter for downtown New York that is providing services, advocacy, research, and information to empower the lower Manhattan. Just like the additional security and sanitation, free transportation in lower Manhattan, streetscape and also design services, economic development, comprehensive research on lower Manhattan, marketing and communication, programming. Downtown New York is providing all of it for a clean environment, safe and dynamic environment for the worker, the community, and also the visitor.

The pivotal topic explains@NYSE tweet delivering@pivotal which is ready for tomorrow, which means that@pivotal listed in NYC on 19 April 2018, and on 20 April 2018 and @NYSE delivering congratulations. Pivotal is the software company and also services that located in San Francisco Palo Alto, California, and there are also some branches in places in America. The division of the pivotal is the pivotal labs, which is the consultation services, the pivotal cloud foundry and also a group that is developing a big data products.

The fearless girls are discussing a bronze statue made by Kristen Visbal. The launch in his new house that is in front of the New York Stock Exchange on 10 December 2018. The launch conducted by the New York City and also the global advisor for State Street. Fearless girl located on 7 March 2017 in the block Bowling Green, finance district Manhattan, New York City. The statue aimed to promote stock related to the stocks lead by a woman.

The topics listed company discussing the companies listed at NYSE, just as the tweet statement on 3 January 2018. @NYSE is celebrating 13 years of the company listed in @NYSE. The stock certificate Sunday delivered @NYSE on 2017, the stock certificate of the company is the certificate of the stock of the company that joined @ NYSE on the previous year before.

On 11 April 2018,@NYSE discussing the \#Straightfrom the floor. This hashtag is to deliver information that is delivered by@NYSE right from the stock activities — earning that discussed @NYSE. On 17 January 2018 is the creation of revenue related to blockchain.

Blockchain is a system that did not use a third party. Bottom line, every transaction that happens will be recorded, recorded in the computer that distributed within the system. The blockchain aims to cover the system 
from a virus on the computer. Therefore the possibility is very slight to have problems at the same time on all computer.

On 18 January 2018, @NYSE posting information that distributed by at @ICEDataServices. @ICEDataServices which is the services information of ICE data and also a block stream that have the benefit to consolidating the main currency.

@NYSE also delivering Quintana energy services officially, the post was online on February 2018. Quintana Energy Services is a growth-oriented company which is problem solution-oriented and also could overcome many problems for services and customer exploration and production based on landed and also the unconventional resources in the USA.

The oil topic also discussed @NYSE, including information about the Liberty Oil Field Service, which is officially open and also the tweet posted on 12 January 2018. Liberty Oil Field Service is the leading hydrologic partner services company. They use analytical data for the activities.

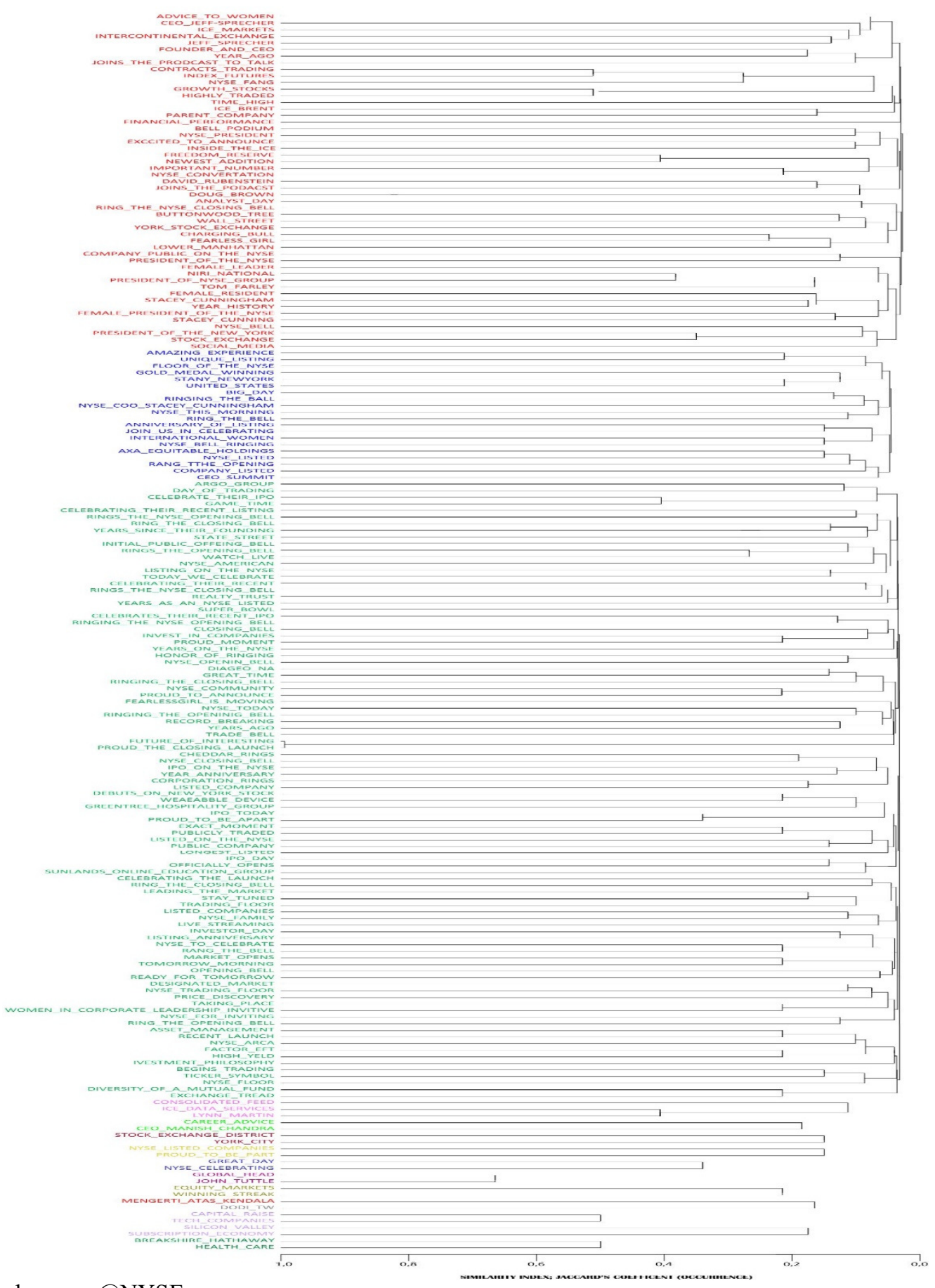

Figure 2. Dendrogram @NYSE 


\section{Conclusion}

The exploratory of unstructured data set @NYSE shows that most of the topics are discussing the stock exchange activities such as the IPO of the new listed stock, the anniversary of stocks listed @NYSE, the information about data availability related to stock traded, the discussion and talk show program from podcast and television. Just like the other channel for the stock exchange, @NYSE also discussing the IPO of the new stocks, nevertheless there is also an anniversary of the stocks that have been 13 years@NYSE.

@NYSE is also delivering information related to how the customers could use the data from the ICE market for analyzing and also on deciding on exchange trade. The exciting part is @NYSE also promoting a discussion on stocks in the other channel which is from the fox news, from the podcast Jeff Preacher. Moreover, there is also Kristen that is delivering news related to finance.

From this tweet, we could see that @NYSE are using Twitter with the integration related to the other channel like the television to deliver information. There is also information related to data and knowledge analysis, which is essential for the decision maker.

There is also some information related to @NYSE COO Stacey Cunning. Finally, there is also information about the fearless girl, which is interesting because they are making some event related to the stock that is managed by a woman. The phenomena are growing in the United States of America. Therefore the topic of fearless girls has their own audience.

\section{References}

Al-Nasseri, A., \& Menla Ali, F. (2018). What does investors' online divergence of opinion tell us about stock returns and trading volume? Journal of Business Research, 86, 166-178. doi:https://doi.org/10.1016/j.jbusres.2018.01.006

Atkins, A., Niranjan, M., \& Gerding, E. (2018). Financial news predicts stock market volatility better than close price. The Journal of Finance and Data Science. doi:https://doi.org/10.1016/j.jfds.2018.02.002

Campbell, C., Pitt, L. F., Parent, M., \& Berthon, P. (2011). Tracking Back-Talk in Consumer-Generated Advertising: An Analysis of Two Interpretative Approaches. Journal of advertising research, 51(1), 224. doi:10.2501/jar-51-1-224-238

Corea, F. (2016). Can Twitter Proxy the Investors' Sentiment? The Case for the Technology Sector. Big Data Research, 4, 70-74. doi:https://doi.org/10.1016/j.bdr.2016.05.001

Dörre, J., Gerstl, P., \& Seiffert, R. (1999). Text mining: finding nuggets in mountains of textual data. Paper presented at the Proceedings of the fifth ACM SIGKDD international conference on Knowledge discovery and data mining.

Feldman, R., \& Hirsh, H. (1996). Mining Associations in Text in the Presence of Background Knowledge. Paper presented at the KDD.

Hair, J. F., Anderson, R. E., Tatham, R. L., \& William, C. (1998). Multivariate data analysis.

Harwani, Y., \& Sihite, J. (2019). The Marketing Mix Element of the Coffee Shop. A Case Study @CoffeeBeanIndo. European Journal of Business and Management, 11(18), 169-174. doi:10.7176/EJBM/11-18-20

Kumar, B. S., \& Ravi, V. (2016). A survey of the applications of text mining in financial domain. KnowledgeBased Systems, 114, 128-147. doi:https://doi.org/10.1016/j.knosys.2016.10.003

Liu, L., Wu, J., Li, P., \& Li, Q. (2015). A social-media-based approach to predicting stock comovement. Expert Systems with Applications, 42(8), 3893-3901. doi:https://doi.org/10.1016/j.eswa.2014.12.049

Mazboudi, M., \& Khalil, S. (2017). The attenuation effect of social media: Evidence from acquisitions by large firms. Journal of Financial Stability, 28, 115-124. doi:https://doi.org/10.1016/j.jfs.2016.11.010

Nasseri, A. A., Tucker, A., \& de Cesare, S. (2015). Quantifying StockTwits semantic terms' trading behavior in financial markets: An effective application of decision tree algorithms. Expert Systems with Applications, 42(23), 9192-9210. doi:https://doi.org/10.1016/j.eswa.2015.08.008

Nugroho, A. (2017). ASEAN Tourism Marketing Communication Attribute: An Exploratory Research at Goaseantv. European Research Studies Journal, XX(3).

Nugroho, A. (2018a). Analisis Faktor Eksploratori Layanan@syariahmandiri.Jurnal Ekonomi, XXIII(3), 376-388.

Nugroho, A. (2018b). The Hospitality Marketing Communication Attribute. A Case Study @hrhbali (Hard Rock Hotel Bali). Journal of Marketing and Consumer Research, 50.

Nugroho, A., \& Sihite, J. (2015a). Is It A Relational Marketing Strategy? Cluster Analysis @,Universitasmercubuanajakarta Facebook Post and Comment. Manajemen MIX, V(2).

Nugroho, A., \& Sihite, J. (2015b). Is It Traditional or Contemporary Marketing Strategy? A Textual Cluster Analysis@MercuBuana_Reg. Mediterranean Journal of Social Sciences, VI(5).

Nugroho, A., \& Sihite, J. (2015). Tweeting And Retweeting Tourism And Airline Service Attributes. Thomson Reuter Indexed Proceeding. International Geographical Union \& Lombok International Conference. University Mataram.

Nugroho, A., \& Sihite, J. (2016). Exploratory Factor Analysis Syariahmandiri and Bankmandiri Service Attributes 
2015. . The Social Sciences, 11, 4896-4901.

Nugroho, A., \& Sihite, J. (2018). ASEAN Tourism Destination: A Strategic Plan. European Research Studies Journal, 21(3), 293-298.

Nugroho, A., Sihite, J., \& Harwani, Y. (2019). The Promotion, Product and the People of Luxurious Hotel: A Case Study@hrhbali 2018. Journal of Tourism, Hospitality and Sports, 41, 73-78. doi:10.7176/JTHS/41-01

Oliveira, N., Cortez, P., \& Areal, N. (2017). The impact of microblogging data for stock market prediction: Using Twitter to predict returns, volatility, trading volume and survey sentiment indices. Expert Systems with Applications, 73, 125-144. doi:https://doi.org/10.1016/j.eswa.2016.12.036

Salton, G., \& McGill, M. J. (1983). Introduction to modern information retrieval: mcgraw-hill.

Sihite, J. (2019a). The Online Transportation Marketing Mix CoCreation: A Case Study@gojekindonesia. Journal of Marketing and Consumer Research, 57, 44-50. doi:10.7176/JMCR/57-05

Sihite, J. (2019b). The Promotion and Process Attribute for the Kitchen Appliance. A Case Study (a)KitchenAid_Indo. European Journal of Business and Management, 11(18), 164-168. doi:10.7176/EJBM/11-18-19

Sihite, J., Harun, T. W., \& Nugroho, A. (2015). The Low Cost Airline Consumer Price Sensitivity. An Investigation on The Mediating Role of Promotion and Trust in Brand. International Research Journal of Business Studies, VII(3).

Sihite, J., \& Nugroho, A. (2018). Exploring the Indonesian Tourism Destination via Indonesia.Travel @indtravel.

Silver, C., \& Lewins, A. (2014). Using software in qualitative research: a step-by-step guide.

Tu, W., Yang, M., Cheung, D. W., \& Mamoulis, N. (2018). Investment recommendation by discovering highquality opinions in investor based social networks. Information Systems. doi:https://doi.org/10.1016/j.is.2018.02.011

Uysal, A. K., \& Gunal, S. (2014). The impact of preprocessing on text classification. Information Processing \& Management, 50(1), 104-112.

Wei, W., Mao, Y., \& Wang, B. (2016). Twitter volume spikes and stock options pricing. Computer Communications, 73, 271-281. doi:https://doi.org/10.1016/j.comcom.2015.06.018

Wijanto, S. H. (2008). Structural Equation Modeling dengan LISREL 8.8: Konsep dan Tutorial.

Yang, Y., \& Pedersen, J. O. (1997). A comparative study on feature selection in text categorization. Paper presented at the Icml.

Zhang, X., Fuehres, H., \& Gloor, P. A. (2011). Predicting Stock Market Indicators Through Twitter "I hope it is not as bad as I fear". Procedia - Social and Behavioral Sciences, 26, 55-62. doi:https://doi.org/10.1016/j.sbspro.2011.10.562 